\title{
miR-31 is consistently inactivated in EBV-associated nasopharyngeal carcinoma and contributes to its tumorigenesis
}

\author{
Chartia Ching-Mei Cheung ${ }^{1}$, Grace Tin-Yun Chung ${ }^{1}$, Samantha Wei-Man Lun ${ }^{1}$, Ka-Fai To ${ }^{1,2}$, Kwong-Wai Choy ${ }^{3}$, \\ Kin-Mang Lau', Sharie Pui-Kei Siu', Xin-Yuan Guan ${ }^{4}$, Roger Kai-Cheong Ngan ${ }^{5}$, Timothy Tak-Chun Yip ${ }^{5}$, \\ Pierre Busson ${ }^{6}$, Sai-Wah Tsao ${ }^{7}$ and Kwok-Wai Lo ${ }^{1,2^{*}}$
}

\begin{abstract}
Background: As a distinctive type of head and neck cancers, nasopharyngeal carcinoma (NPC) is genesis from the clonal Epstein-Barr virus (EBV)-infected nasopharyngeal epithelial cells accumulated with multiple genetic lesions. Among the recurrent genetic alterations defined, loss of 9p21.3 is the most frequent early event in the tumorigenesis of EBV-associated NPC. In addition to the reported CDKN2AN16, herein, we elucidated the role of a miRNA, miR-31 within this 9p21.3 region as NPC-associated tumor suppressor.

Methods: The expression and promoter methylation of miR-31 were assessed in a panel of NPC tumor lines and primary tumors. Its in vitro and in vivo tumor suppression function was investigated through the ectopic expression of miR-31 in NPC cells. We also determined the miR-31 targeted genes and its involvement in the growth in NPC.

Results: Downregulation of miR-31 expression was detected in almost all NPC cell line, patient-derived xenografts (PDXs) and primary tumors. Both homozygous deletion and promoter hypermethylation were shown to be major mechanisms for miR-31 silencing in this cancer. Strikingly, loss of miR-31 was also obviously observed in the dysplastic lesions of nasopharynx. Restoration of miR-31 in C666-1 cells inhibited the cell proliferation, colony-forming and migratory capacities. Dramatic reduction of in vitro anchorage-independent growth and in vivo tumorigenic potential were demonstrated in the stable clones expressing miR-31. Furthermore, we proved that miR-31 suppressed the NPC cell growth via targeting FlH1 and MCM2.
\end{abstract}

Conclusions: The findings provide strong evidence to support miR-31 as a new NPC-associated tumor suppressor on 9p21.3 region. The inactivation of miR-31 may contribute to the early development of NPC.

Keywords: Nasopharyngeal carcinoma, MicroRNA, miR-31, FIH1, MCM2

\section{Background}

MicroRNAs, about 21-25 nucleotides in length, are endogenous non-coding RNAs that regulate gene expression negatively at post-transcriptional level [1,2]. Increasing evidence indicates that microRNAs can contribute to the tumorigenesis process by modulating various cellular mechanisms, such as proliferation, apoptosis, and cell

\footnotetext{
* Correspondence: kwlo@cuhk.edu.hk

'Department of Anatomical and Cellular Pathology, State Key Laboratory in Oncology in South China, Prince of Wales Hospital, The Chinese University of Hong Kong, Hong Kong, People's Republic of China

${ }^{2}$ Li Ka Shing Institute of Health Science, The Chinese University of Hong Kong, Hong Kong, People's Republic of China

Full list of author information is available at the end of the article
}

migration and invasion. To date, a number of host- and virus-encoded microRNAs were demonstrated to be aberrantly expressed and play important roles in the development of human cancers $[3,4]$.

Nasopharyngeal carcinoma (NPC) is an Epstein-Barr virus (EBV)-associated epithelial malignancy that is prevalent in Southern China and Southeast Asia. In addition to EBV infection, a number of recurrent genetic changes contribute to NPC multi-step tumorigenesis. Through comprehensive investigation of a panel of precancerous lesions and normal nasopharyngeal epithelia, we have previously demonstrated the occurrence of allelic loss 
on chromosome 3p and 9p prior to EBV latent infection during the initiation of NPC [5,6]. Inactivation of the key tumor suppressor genes on these regions such as RASSF1A (3p21.3) and p16/CDKN2A (9p21.3) were proven to be critical events in NPC tumorigenesis. Recently, we investigated the miRNA profiles of a panel of EBVassociated NPC tumor lines and identified several differentially expressed miRNAs that may contribute to NPC development. Among the aberrantly expressed miRNAs identified, the miR-31, which is located on the common homozygous deletion region on chromosome 9p21.3 and adjacent to the $p 16 / C D K N 2 A$ locus, is consistently downregulated in NPC [7]. Since down-regulation of miR-31 contributes to the progression of prostate, ovarian, and breast cancers, we hypothesize that $m i R-31$ is one of the critical NPC-associated tumor suppressor on chromosome $9 \mathrm{p}$ and may involve in the early development of this cancer [8-10]. Herein, we revealed the mechanisms involved in the inactivation of $m i R-31$, identified the direct targets and demonstrated its tumor suppressor function in NPC cells. Our study provides strong evidence that inactivation of $m i R-31$ in the 9p21.3 tumor suppressor loci is an important event in NPC tumorigenesis.

\section{Results}

\section{Consistent down-regulation of miR-31 in NPC}

In our earlier studies, homozygous deletion of 9p21.3 including the $C D K N 2 A / C D K N 2 B$ loci was commonly found in EBV-associated NPC [11]. In addition to the well-known tumor suppressor function of $p 16 / C D K N 2 A$, it is suspected that inactivation of other candidate genes in this region may also contribute to the NPC tumorigenesis. $M i R-31$, which is at $0.5 \mathrm{Mb}$ telomeric to the CDKN2A/p16 loci, was shown to function as tumor suppressor microRNA in various human cancers $[7,12,13]$. Using microRNA microarray, we examined the microRNA expression profiles in the immortalized nasopharyngeal epithelial cell NP69 and a panel of NPC cell line and patient derived xenografts (PDXs). Hierarchical clustering with average linkage algorithm was performed and a heat map of the expression profiles was generated (Additional file 1: Figure S1). Among the 115 differentially expressed miRNAs identified, we noted that the $m i R-31$ expression was highly reduced in 5/6 NPC xenografts. This preliminary finding suggested the inactivation of $m i R-31$ is common in this EBV-associated cancer. To confirm the frequent downregulation of $m i R-31$ in NPC, we have assessed its expression in a panel of tumor lines and microdissected primary tumors by stem-looped qRT-PCR. As shown in Figure 1A, miR-31 expression was highly reduced in 5 of 6 (83.3\%) EBV-positive xenografts and in all 37 (100\%) primary tumors (Figure 1a and $1 \mathrm{~b}$ ). Down-regulation of $m i R-31$ was also detected in the EBV-positive NPC cell line C666-1 which is originally derived from xeno-666.
Abundant $m i R-31$ transcription was only detected in the C15 xenograft which expresses EBV-encoded LMP1 protein (Figure 1a). In Figure 1c, in-situ hybridization analysis demonstrated the high $m i R-31$ expression in normal nasopharyngeal epithelia and down-regulation of $m i R-31$ in the tumor cells of representative cases. Importantly, down-regulation of $m i R-31$ was also obviously detected in 2/4 dysplastic lesions which we collected in our previous studies (Figure 1d) $[14,15]$. Our finding not only revealed the consistent inactivation of $m i R-31$ in EBV-associated NPC, it also provided first evidence for the involvement of $m i R-31$ down-regulation in the early development of NPC.

\section{Homozygous deletion and promoter hypermethylation of $\mathrm{miR}-31$}

Homozygous deletion of $p 16 / C D N K 2 B$ locus on $9 \mathrm{p} 21.3$ was previously reported and identified by aCGH analysis in 3 PDXs (xeno-2117, xeno-1915 and xeno-99186) (Additional file 2: Figure S2) [11,16]. It is suspected that the down-regulation of $m i R-31$ in these tumors is due to complete loss of the $m i R-31$ allele. However, detailed mapping of the deletion regions by multiple PCR analysis demonstrated that $m i R-31$ locus was deleted in only 2 out of 6 xenografts (33.3\%; xeno-1915 and xeno-99186) (Figure 2a). The expression of $m i R-31$ was regulated by the promoter of its host gene LOC554202 (Figure 2a). Hypermethylation of the LOC554202-associated 5 'CpG islands can lead to the transcription silencing of $m i R-31$ [17]. In the 4 NPC tumor lines with $m i R-31$ down-regulation, heavy methylation of the $5^{\prime} \mathrm{CpG}$ islands was detected by bisulfite sequencing and methylationspecific PCR (Figure 2b and 2c). Notably, promoter hypermethylation of $m i R-31$ was commonly found in the primary tumors $(14 / 16 ; 87 \%)$ (Figure $2 b)$. As shown in Figure $2 \mathrm{~d}$, re-expression of $m i R-31$ and unmethylated allele were detected in the C666-1 cells treated with a DNA methylation inhibitor, 5'-aza-2'deoxycytidine (5-Aza-dC). The findings indicated that homozygous deletion and methylation of 5' CpG islands are the major mechanisms for $m i R-31$ inactivation in NPC.

\section{miR-31 inhibits cell proliferation, viability and migration in NPC cells}

To explore the tumor suppressor function of $m i R-31$ in NPC cells, the C666-1 cells, in which miR-31 transcripts are downregulated, were transiently transfected with miR-31 mimic or corresponding control. By WST-1 assay, we demonstrated that ectopic expression of $m i R-31$ significantly inhibited the cell proliferation and viability of C666-1 cells (Figure 3a). The miR-31 expression also suppressed the clone formation ability of NPC cells. The number of colonies significantly reduced by $66 \%$ in miR-31-transfected C666-1 when compared to that of 


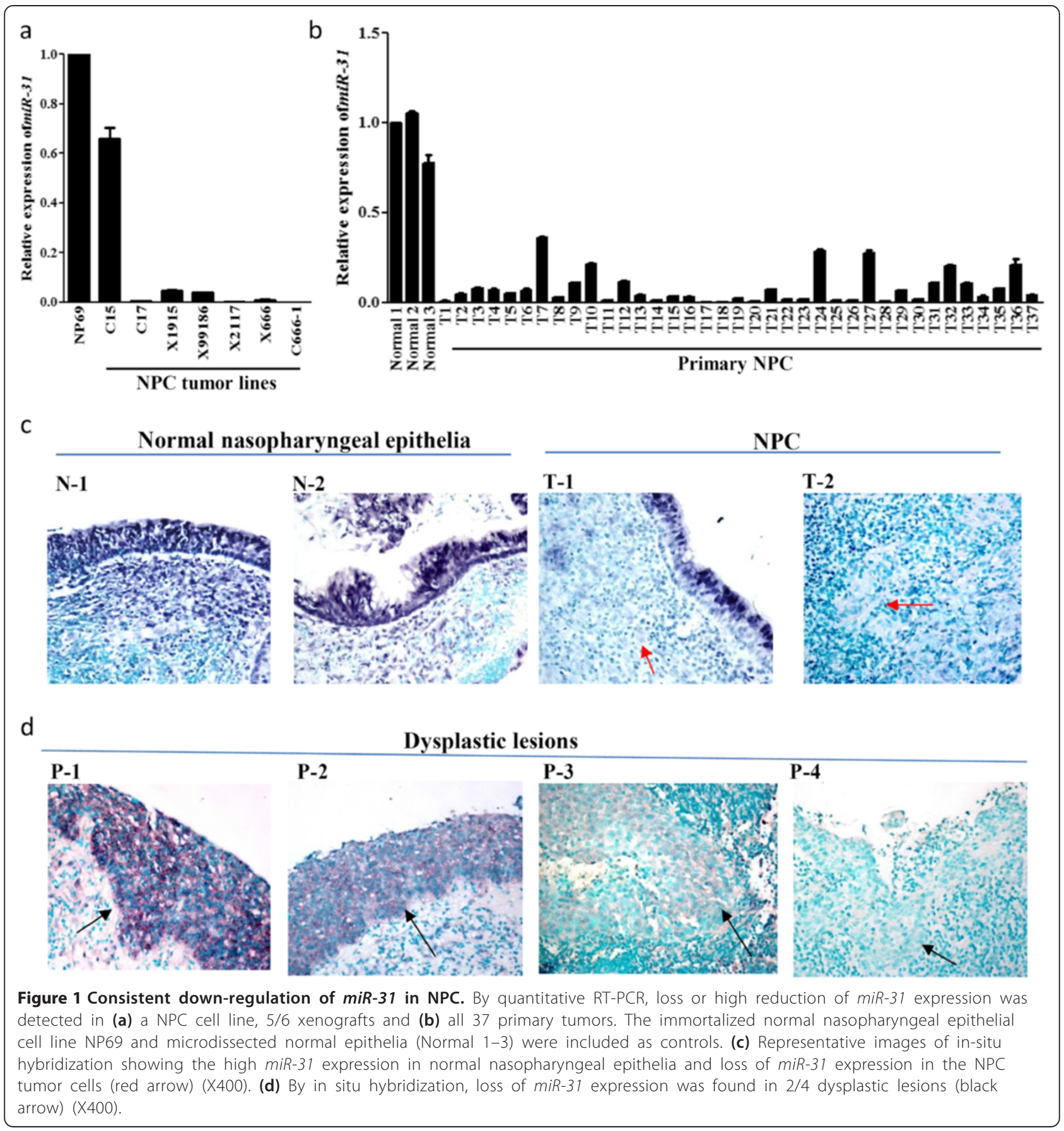

negative control in the colony formation assay (Figure 3b). By flow cytometry, a significant decrease in the percentage of C666-1 cells undergoing S-phase in cell cycle was detected after transient transfection of miR-31 mimic (Figure 3c). In addition, a decrease of $35 \%$ in wound recovery area was measured in miR-31-transfected C666-1 when compared to that of negative control (Figure 3d). This implied that miR-31 expression also inhibited the migratory capacity of NPC cells.
miR-31 suppresses tumorigenicity in vitro and in vivo To further explore whether ectopic expression of miR-31 affects anchorage-independent growth in vitro and tumor growth in vivo, we have established 2 stably transfected C666-1 cell lines (miR-31\#1 and miR-31\#2) expressing different amount of miR31 (Figure 4a). As shown in Figure $4 \mathrm{~b}$, significant suppression in cell proliferation was confirmed in both two stably-miR-31 expressing cells. The stably transfected C666-1 cells with miR-31 


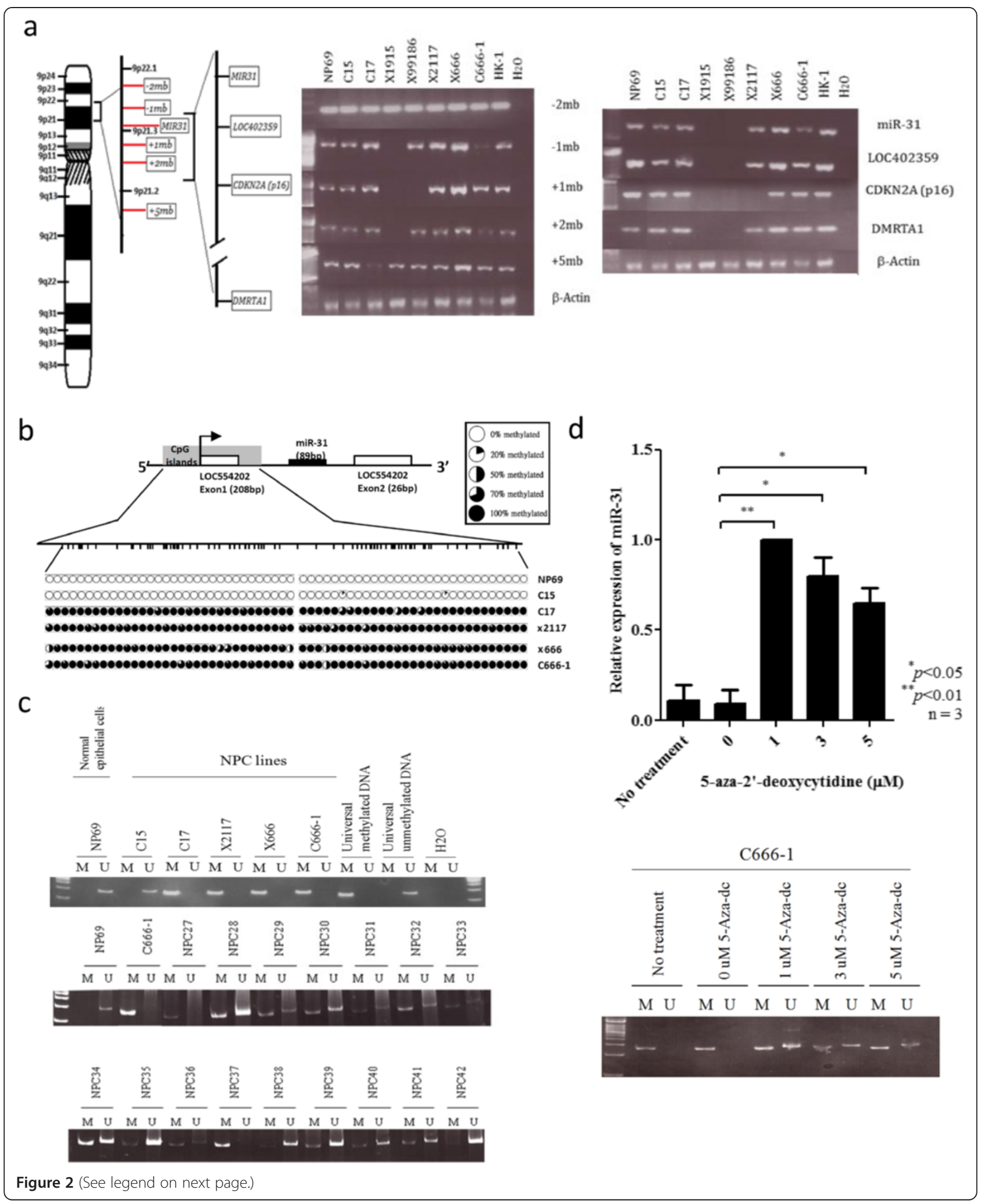


(See figure on previous page.)

Figure 2 Inactivation of miR-31 in NPC. (a) Homozygous deletions of miR-31, adjacent markers $(-2 \mathrm{mb},-1 \mathrm{mb},+1 \mathrm{mb},+2 \mathrm{mb},+5 \mathrm{mb})$ and loci (LOC402359, CDKN2A 16, DMRTA1) in EBV-positive NPC tumor lines were detected by PCR. The location of miR-31 and adjacent markers on chromosome 9p21.3 was shown in the right panel. Homozygous deletions of miR-31 were detected in X1915 and X99186. (b) Methylation status of $5^{\prime} \mathrm{CpG}$ islands of miR-31 in NPC tumor lines was examined by bisulfite sequencing. The locations of miR-31 and its host gene LOC554202 were indicated. Dense methylation of 5' $\mathrm{CpG}$ islands were detected in the C666-1 cell lines and 3 xenografts (C17, X2117 and X666). No methylation were observed in the normal control, NP69. (c) Detection of promoter hypermethylation of NPC cell lines and primary tumors by MSP. M: methylated allele; $\mathrm{U}$ : unmethylated alleles. (d) The restoration of miR-31 transcription in 5'-aza-2'deoxycytidine (5-Aza-dC) treated C666-1 was detected by quantitative RT-PCR analysis. By MSP, unmethylated alleles of miR-31 were found in the 5-Aza-dC-treated C666-1 cells.
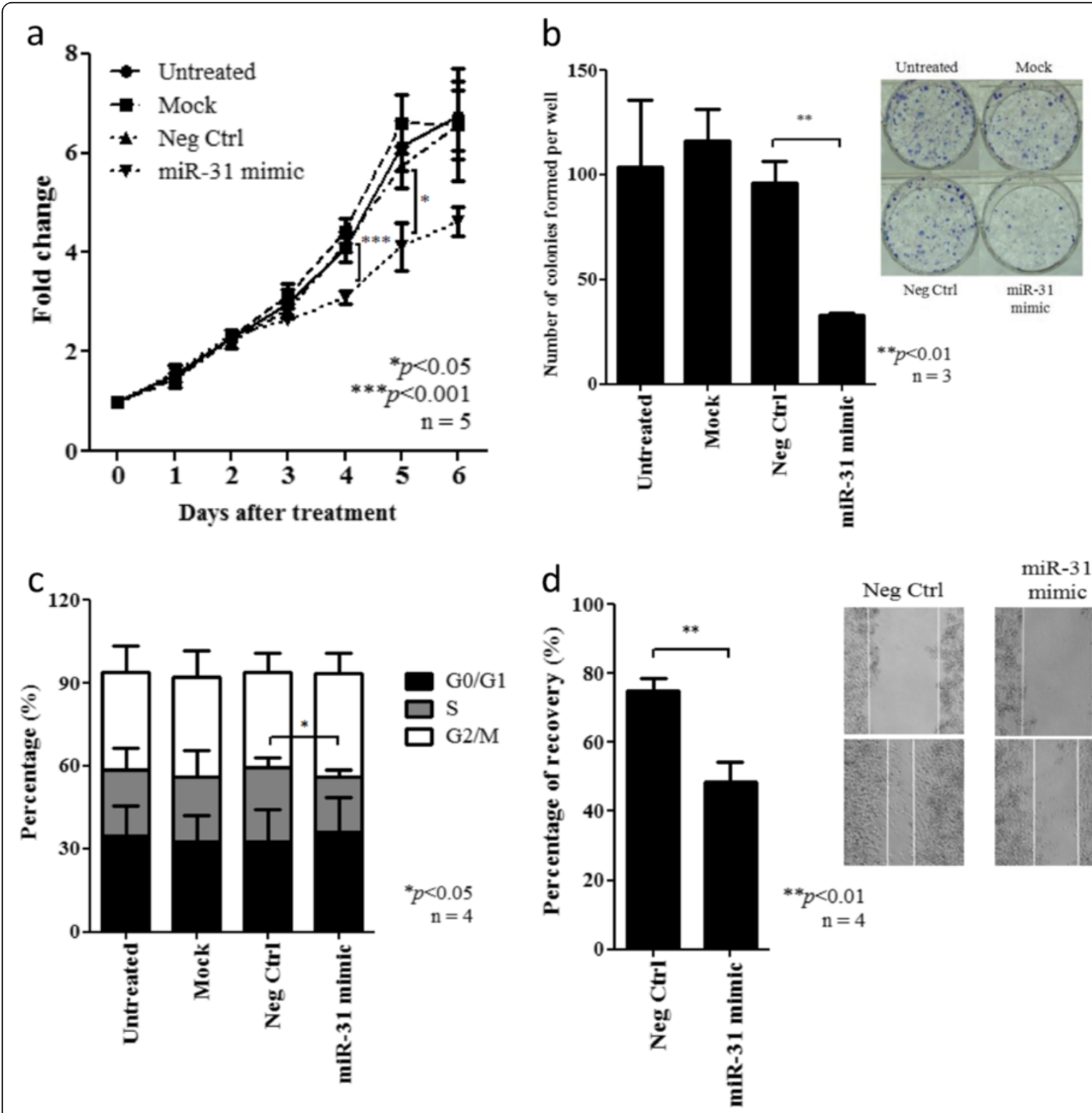

Figure 3 Effect of miR-31 expression on cell growth and migration of NPC cells. (a) By WST-1 assay, significant growth inhibition was detected in the C666-1 cell transfected with miR-31 when compared with negative control. Data shown were taken from 5 independent experiments with mean \pm SEM. (b) Expression of miR-31 significantly inhibited the colony-forming ability of C666-1 cells $\left({ }^{* *} \mathrm{p}<0.01\right)$. Representative photographs of colonies formed in each treatment were shown. Colonies formed were stained in blue by Giemsa stain. (c) Flow cytometry analysis revealed significant reduction of the percentage of cells undergoing $S$ phase in miR-37-transfected C666-1 cells $\left({ }^{*} p<0.05\right)$. (d) By wound healing assay, significant reduction of the migration ability of miR-31-expressing C666-1 (**P $<0.01$ ). Representative photographs of wound healing progress of C666-1 cells transfected with negative control and miR-31 at 0 hour and 30 hours were shown. 


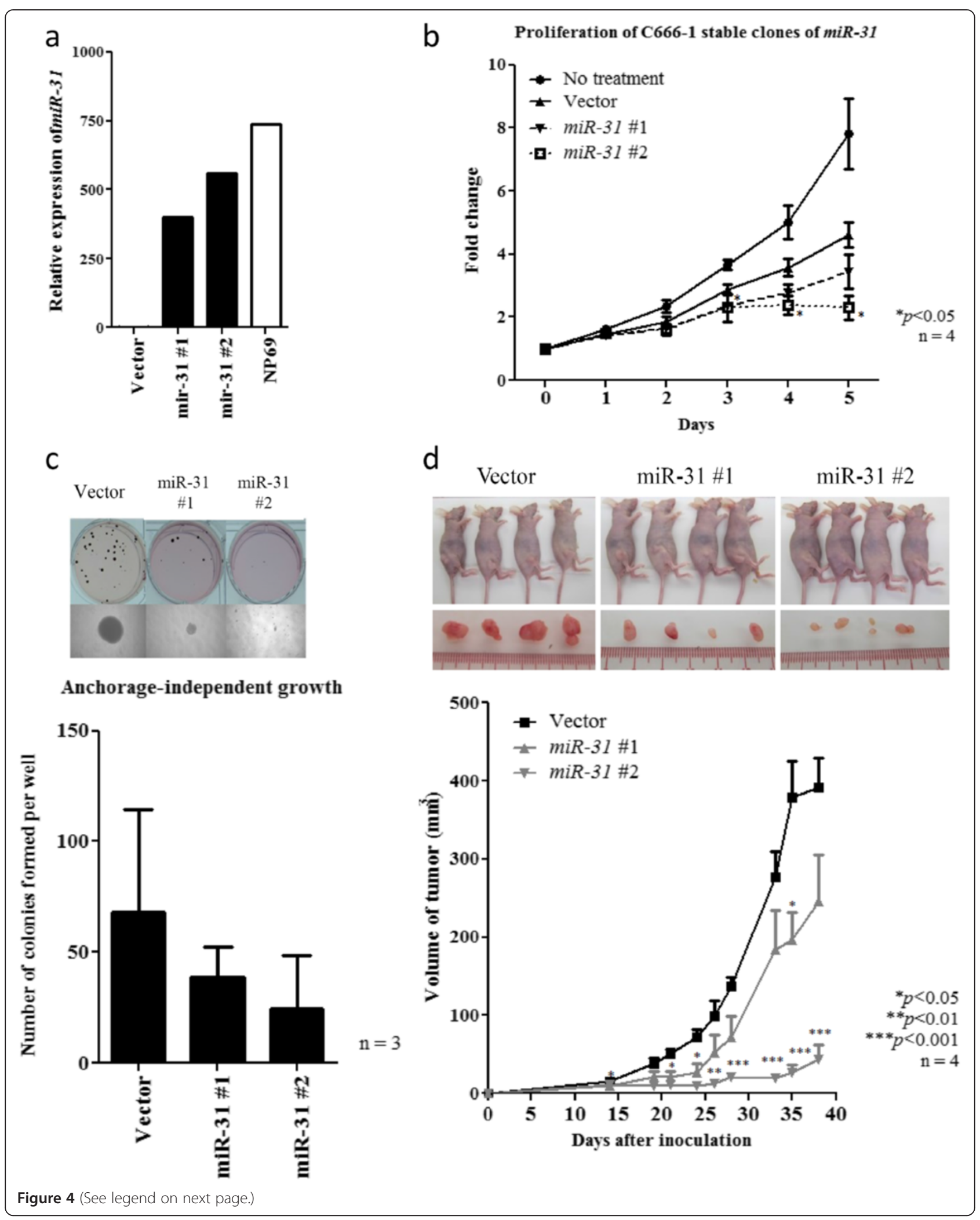


(See figure on previous page.)

Figure 4 Stable ectopic miR-31 expression suppresses the anchorage-independent growth and in vivo tumorigenicity of NPC cells. (a) Expression of miR-31 was demonstrated in the stably miR-31-transfected C666-1 cell clones (miR31\#1 and miR31\#2) by quantitative RT-PCR. The immortalized normal nasopharyngeal epithelial cells NP69 was included as control. (b) In the two stably miR-37-transfected NPC cell clones (miR31\#1 and miR31\#2), obvious growth inhibition was demonstrated by WST-1 assay. (c) Stable expression of miR-31 inhibits the anchorage-independent growth of C666-1 cells. Obviously reduction in number and size of colonies in the stable miR-31-expressing cells were demonstrated by soft agar assay. (d) In vivo tumorgenic assay in nude mice showed that tumors formed in the sites implanted with C666-1 cells expressing miR-31 (miR-31\#1 and miR-31\#2) were consistently smaller than those implanted with vector controls. Photographs showing the nude mice (upper row) inoculated with stable clones (vector, miR-31 \#1, \#2) and tumors extracted (bottom row) on day 38 after inoculation were also shown. Four nude mice were used in the experiment and data was shown with mean \pm SEM. Student-t test was used for statistical significance, with a p-value of less than 0.05 was considered significant $\left({ }^{*} p<0.05,{ }^{* *} p<0.01,{ }^{* * *} p<0.001\right)$.

showed obvious repression of anchorage-independent growth. The cells expressing $m i R-31$ displayed much fewer and smaller colonies in the soft agar compared with controls (Figure 4c). To investigate the effect of $m i R-31$ on in vivo tumor growth, the stably $m i R-31$-expressing C666-1 cells and controls were subcutaneously injected into nude mice. As shown in Figure 4d, tumor growth by $m i R$-31-expressing cells was significantly inhibited when compared to those transfected with control vector. Notably, the stronger inhibitory effects on in vitro and in vivo tumor growth were found in the miR-31\#2 clone which expressed higher level of $m i R-31$. Our study demonstrated a dose-dependent tumor suppressor effect of miR-31 in NPC cells.

\section{MCM2 and FIH1 as target of miR-31 in NPC}

To investigate the mechanism by which miR-31 suppressed the tumor cell growth in NPC, we validated a number of candidate targets of miR-31 which are reported previously or predicated by the TargetScan and miRanda database. We found that miR-31 expressed did not inhibit the expression of NIK, E2F2, RDX, RhoA, MCM7 in C666-1 cells (Additional file 3: Figure S3). Only FIH1 and MCM2 expression was obviously repressed by the $m i R-31$ in NPC cells (Figure 5a). Overexpression of these two proteins was commonly found in the NPC tumor lines (Additional file 4: Figure S4). By luciferase reporter assay, FIH1 and MCM2 were further confirmed to be direct targets of $m i R-31$ in C666-1. The binding of miR-31 to the 3' UTR of these genes markedly inhibited luciferase activity (Figure 5b). As shown in Figure 5, miR-31 highly suppressed the expression of MCM2 and FIH1 in NPC cells. The finding confirmed $F I H 1$ and $M C M 2$ are direct targets of miR-31 in NPC. MCM2 is a well-known component of the minichromosome maintenance (MCM) proteins $2-7$ complex which plays crucial roles in DNA replication licensing. The important role of MCM2 in tumorigenesis has also been demonstrated in our previous report [18]. In this study, we also knocked down the expression of MCM2 in NPC C666-1 cells by siRNAs (Figure 6a). Significant growth inhibition of the C666-1 cells with MCM2 depletion was observed (Figure 6b). It indicated that $m i R-31$ may modulate NPC cell growth via repressing MCM2 expression. To further explore whether FIH1 is the target associated with the tumor suppressor function of $m i R-31$, we knocked down the expression of FIH1 by siRNAs in C666-1 cells and assessed its effects on growth inhibition (Figure 7a). As shown in Figure 7b, by WST-1 assay, the proliferation of C666-1 cells was significantly inhibited by the treatment of siRNAs targeting FIH1. Furthermore, we also found that $F I H 1$ knockdown enhanced Ser15 phosphorylation of p53 and up-regulated p21 expression (Figure 7c). The finding confirmed FIH1 function in the suppression of p53 activity as reported previously [19]. Since a majority of NPC contains the wild-type $p 53$, down-regulation of miR-31 is believed to be an important mechanism for impairing $p 53$ tumor suppressor function in this EBV-associated cancer.

\section{Discussion}

NPC is a distinctive type of head and neck cancer which is consistently associated with EBV infection and prominent lymphoplasmacytic infiltration. Based on the studies on premalignant lesions and invasive cancers, we have proposed a model of NPC tumorigenesis, in which EBV infection and inactivation of multiple tumor suppressors on chromosomes $3 p$ and $9 p$ play crucial roles in the initiation process. The inactivation of RASSF1A on 3p21.3 was shown to be an early event in NPC development [20]. On chromosome $9 \mathrm{p}$, we have previously demonstrated the consistent inactivation of $p 16$ on $9 \mathrm{p} 21.3$ in the primary tumors and precancerous lesions. In addition to a loss of growth inhibitory effects, $p 16$ inactivation predisposed nasopharyngeal epithelial cells to persistent EBV latent infection [15]. miR-31 is a cancer-associated microRNA at $0.5 \mathrm{Mb}$ telomeric to the $p 16$ locus and commonly deleted in various human cancers including melanoma, mesothelioma and urothelial carcinoma $[7,21,22]$. In this study, we clearly demonstrated that miR-31 is consistently inactivated in NPC by either homozygous deletion or promoter methylation. As shown in the xenografts, both miR-31 and $p 16$ loci are located in the common homozygous deletion region of NPC (Figure 2a). Notably, loss of $m i R-31$ expression was also detected in the pre-invasive lesions 

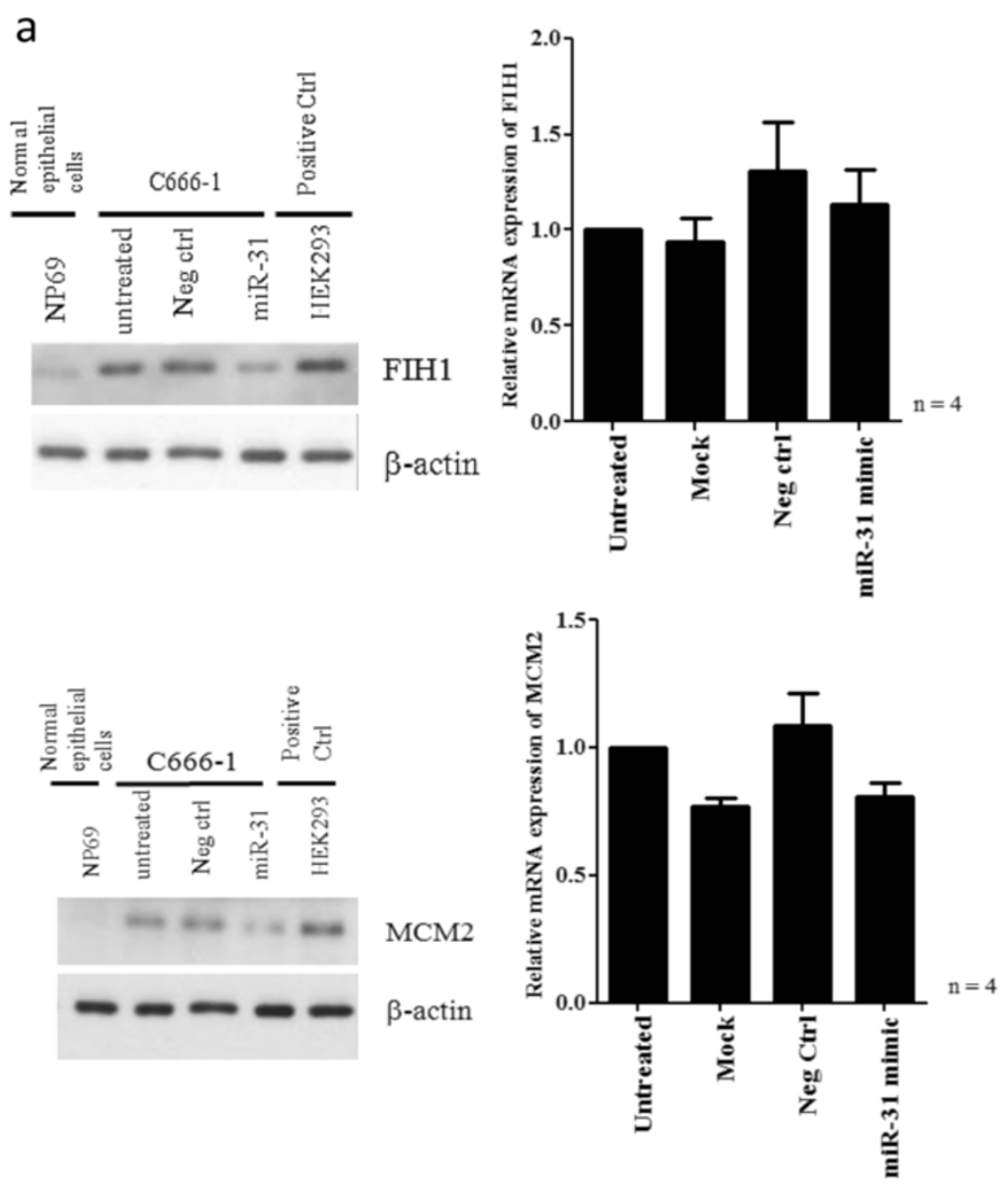

b
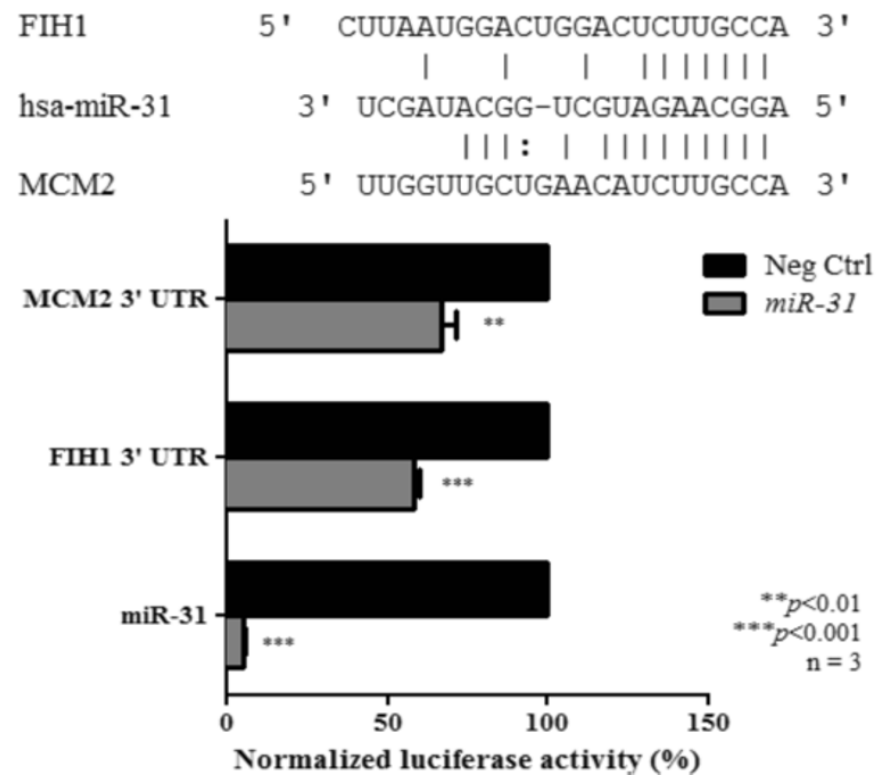

Figure 5 (See legend on next page.) 
(See figure on previous page.)

Figure 5 miR-31 suppresses FIH1 and MCM2 expression in NPC cells. (a) Protein expression of FIH1 and MCM2 proteins were reduced in the C666-1 cells transfected with miR-31 when compared with controls (Right panel). By qRT-PCR, no significant changes of FIH1 and MCM2 transcripts were found in the miR-31-transfected C666-1 cells (Left panel). (b) Luciferase reporter assay showing the effects of miR-31 on 3' untranslated region ( $3^{\prime} U T R$ ) of FIH1 and MCM2 mRNA. Luciferase activity was normalized by the renilla luciferase control. The binding of miR-31 on $3^{\prime} U T R$ of FIH1 and MCM2 significantly decreased the luciferase activity. As a control, reporter vector carrying miR-31 complementary sequence in the $3^{\prime}$ UTR were also constructed (miR-31) which upon binding showed a near complete abolishment of miR-31 luciferase activity. Three independent experiments with mean \pm SEM. Student-t test was used for statistical significance, with a $p$-value of less than 0.05 was considered significant $\left({ }^{* *} p<0.01,{ }^{* * *} p<0.001\right)$

although the dysplastic lesions are rare and only limited cases were studied. The findings suggest the crucial role of $m i R-31$ in early development of NPC.

$m i R-31$ acts as tumor suppressor in several human malignancies, such as ATL (adult T cell leukemia), gastric cancer, mesothelioma, and melanoma [7,12,13,23]. Ectopic expression of $m i R-31$ inhibited in vitro cell proliferation and in vivo tumor growth in prostate cancers $[8,24]$. In our study, miR-31 was found capable of inhibiting NPC cell proliferation, anchorage-independent growth, cell migration, and in vivo tumor development. The tumor suppressor properties of $m i R-31$ in EBV-associated NPC were confirmed. The phenotypes resulting from the tumor suppressor miRNA is dependent on its target genes. Although a number of experimental validated $m i R-31$ target genes have been reported, it is likely that

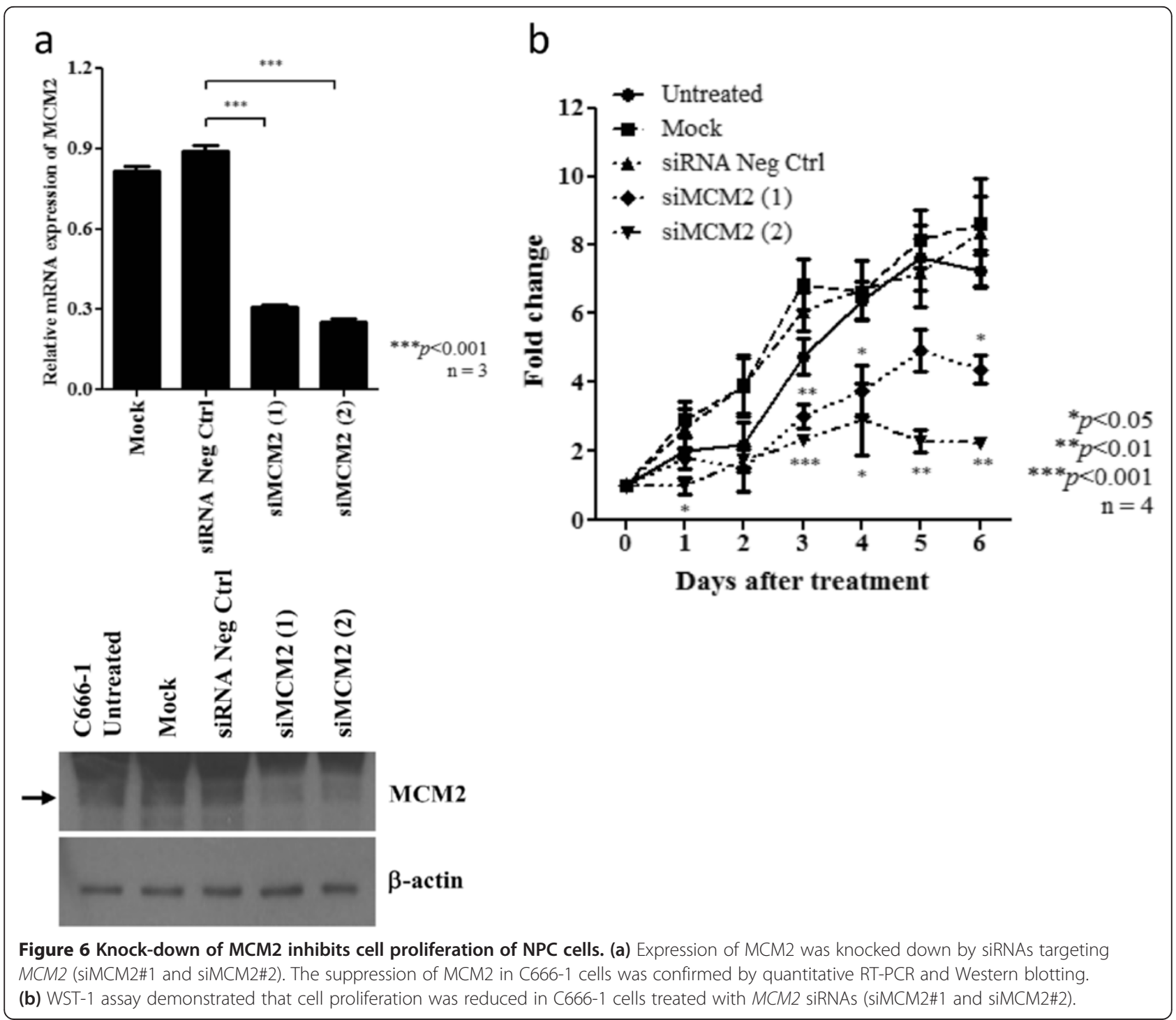




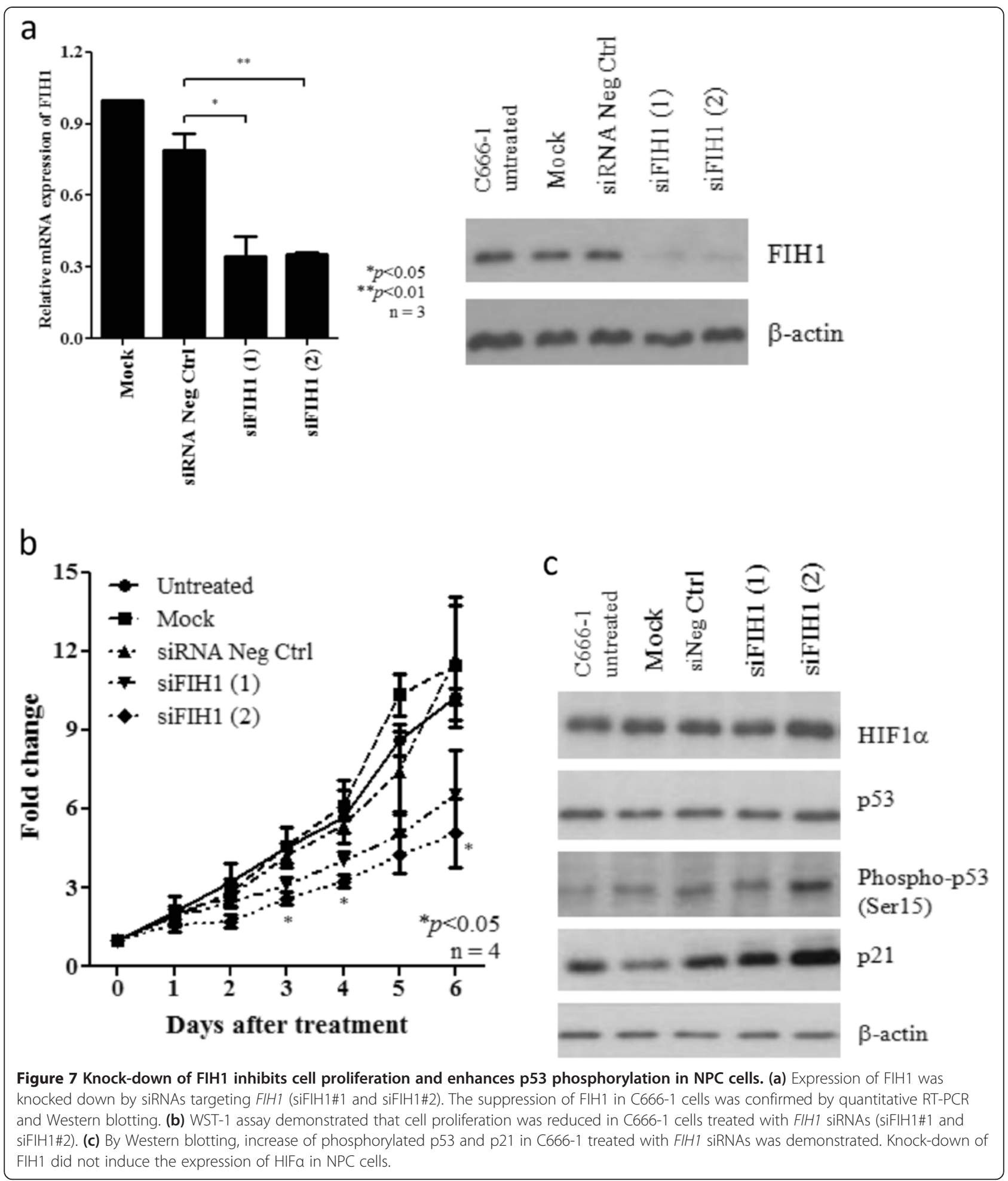

the targets vary from one tumor type to another. Here, we confirmed MCM2 and FIH1 as miR-31 target genes in NPC cells. The growth inhibitory effect of $m i R-31$ in NPC via modulating of MCM2 and FIH1 expression was demonstrated. MCM2 is one of the six components of
MCM protein complex which is important in the initiation of DNA replication. Regulation of MCM2 protein expression by miR-31 was recently reported in prostate cancer [8]. Elevated expression of MCM proteins were detected in both dysplasia and malignancy of various 
tissues [18]. It is believed that deregulation of MCM proteins contribute to the early stage in carcinogenesis. In our earlier study, we demonstrated that knockdown of MCM2 significantly inhibited the cell growth, migration, and invasion in medulloblastoma [18]. Furthermore, the involvement of MCM2 in regulating filopodia and stress fiber formation through cdc42 and Rho activation respectively was shown. Through knocking down of MCM2 by siRNA, studies demonstrated that the MCM2 expression impaired the growth of the prostatic (LNCaP) and colon (HCT116) cancer cell lines [18,25,26]. Similar growth inhibition was also observed in the C666-1 cells with MCM2 depletion. Occurrence of inhibitory phenotypes in the miR-31-expressing NPC cells is suspected to be due to MCM2 repression. Aside from MCM2, the suppressive effect of $m i R-31$ on NPC tumor growth was also via repressing FIH1. Liu et al. first reported miR-31 target FIH1 and thereby activates the HIF pathway in HNSCC [27]. High FIH1 expression contributes to the development of colon carcinomas and melanoma through the suppression of the p53-p21 axis [19]. Interestingly, FIH1 overexpression is also sufficient to inhibit differentiation of primary human corneal epithelial keratinocytes (HCEKs) [28]. Knocking down of FIH1 suppressed the cell proliferation in the clear cell renal cell carcinoma (CCRCC) (RCC10 and RCC4) and colon adenocarcinoma (LS174) cell lines [19,29]. Silencing of FIH1 results in the elevation of p53 activity and p21 expression under normoxia [19]. Here, we also showed an increase in the expression of phospho-p53 (Ser15) and p21 in the NPC C666-1 cells with FIH1 silencing. Since $p 53$ mutation is rare in EBV-associated NPC, impaired p53 function may be associated with high FIH1 expression in this miR-31 deficient cells. Although miR-31 modulated the expression of FIH1 in NPC cells, it did not alter HIF1 $\alpha$ expression as shown in head and neck squamous cell carcinoma (HNSCC) [27]. HIF1 $\alpha$ expression in the C666-1 cells was also not affected by knockdown of FIH1 (Figure 7e). The oncogenic function of FIH1 in NPC cells is likely to be HIF-independent. EBV-encoded LMP1 is capable to upregulate HIF1 $\alpha$ through inducing Siah1 E3 ubiquitin ligase which promotes the degradation of prolyl hydroxylases 1 and 3 in nasopharyngeal epithelial cells [30]. In our study, high miR-31 expression was detected in the xenograft $\mathrm{C} 15$ which shows homogeneous LMP1 expression (Additional file 5: Figure S5). The observation raises the possibility of interplay between these two proteins in NPC. Such potential crosstalk of viral protein and cellular microRNA needs to be further investigate in future study.

\section{Conclusions}

Our study revealed that miR-31 is frequently inactivated in NPC and its inactivation is believed to be an early event in tumorigenesis. miR-31 may target $M C M 2$ and FIH1 and thereby inhibit growth of NPC cells. The significant inhibitory effects of miR-31 on in vitro and in vivo tumorigenicity implied $m i R-31$ as a potential therapeutic target for EBV-associated NPC. Our findings provide important understanding for the further elucidation on the therapeutic use of miRNA in NPC.

\section{Materials and methods}

\section{Cell lines, xenografts and primary tumors}

Six NPC patient-derived xenografts (PDXs) (C15, C17, xeno-2117 (X2117), xeno-666 (X666), xeno-1915 (X1915), and xeno-99186 (X99186)), an EBV-positive NPC cell line (C666-1), and an immortalized normal nasopharynx epithelial cell line (NP69) established by us were used in this study [31-37]. The study also included a total of 37 NPC endoscopic biopsies and 3 normal nasopharyngeal epithelium specimens obtained from NPC patients in Prince of Wales Hospital, The Chinese University of Hong Kong with informed consent. All NPC specimens were taken before treatment and confirmed to be non-keratinizing carcinoma and EBV positive. To enrich the collection of tumor cells or normal nasopharyngeal epithelial cells, microdissection was conducted manually on these samples. DNA and RNA extraction were performed as previously reported [5]. The patient characteristics are listed in Additional file 6: Table S1.

To assess the involvement of promoter methylation in miR-31 silencing, C666-1 cells at 30\% confluence were treated with the demethylation agent 5-aza-2'deoxycytidine (5-Aza-dC; Sigma-Aldrich). Half of the medium was replaced with fresh complete medium containing 5 -Aza-dC every day for 3 days. Cells were harvested on day 4 for DNA or RNA extraction.

\section{PCR and Quantitative RT-PCR}

To delineate the 9p21.3 homozygous deletion region in NPC xenografts, conventional PCR analysis of the loci in this region was performed using multiple primer pairs. The sequences of these primers were listed in Additional file 7: Table S2.

Total RNA from homogenized xenografts and cell lines was extracted using TRIZOL $^{\circ}$ reagent (Life Technologies). Conventional qRT-PCR using SuperScript ${ }^{\text {tu }}$ III Reverse Transcriptase (Life Technologies) was performed for the detection of mRNA expression of target genes as described [38]. For determining microRNA expression, TaqMan MicroRNA Assay (Life Technologies) was performed according to the manufacturer's instructions. The assays employed pre-designed, target-specific stem-loop reverse transcription miRNA primers (Life Technologies) for the mature miRNAs. 


\section{In situ hybridization (ISH) analysis}

By using the miRCURY LNA microRNA ISH Optimization Kit (Exiqon), in situ hybridization was performed to access the miR-31 expression of on the NPC tumor and dysplastic lesions. Four micron paraffin-embedded tissue sections were incubated with proteinase-K buffer (Exiqon) at $37^{\circ} \mathrm{C}$ for 20 minutes after deparaffinization by xylene and rehydration by ethanol. The slides were subjected to hybridization at $55^{\circ} \mathrm{C}$. After washing, the sections were counter-stained with methyl green.

\section{Bisulfite sequencing and Methylation specific-PCR (MSP) analysis}

For examining the methylation status, the DNA samples were subjected to bisulfite modification using EZ DNA Methylation-Gold Kit (Zymo Research). The modified DNA was subjected to bisulfite sequencing and MSP analysis as described $[39,40]$. The primers used were listed in Additional file 7: Table S2.

\section{miR-31 mimic and siRNA transfection}

C666-1 cells were transiently transfected with miR-31 mimic or negative control (Life Technologies). The transfection was performed according to manufacturer's instructions of Lipofectamine 2000 (Life Technologies). Stably transfected C666-1 cells were generated by G418 selection of the clone transfected with miR-31 expressing vector and miR-negative control (Origene) for 40 days. To knock down the expression of FIH1 and MCM2, two independent specific siRNA duplexes for each gene were transfected into C666-1 cells, using LipofectAMINE 2000 (Invitrogen, Carlsbad, CA, USA) as described (Additional file 8: Table S3) [41]. Non-specific control siRNA and reagent control were included in the experiments.

\section{Cell proliferation, colony formation and cell migration assays}

Cell proliferation and anchorage-dependent growth of miR-31-transfected C666-1 cells was determined by performing WST-1 and colony-formation assays as previously described [34]. The cells were also fixed and stained with propidium iodide, and then subjected to flow cytometry analysis using BD FACS Calibur (Becton Dickinson) and FlowJo software (Treestar). The migration capability was determined using wound closure assay as described [42].

\section{Anchorage-independent growth and in vivo tumorigenicity assays}

Stably miR-31-transfected C666-1 and control cells were subjected to the soft agar assay for anchorageindependent growth in $4 \mathrm{~mL}$ medium supplemented with $0.35 \%$ agarose and layered on a $5 \mathrm{~mL}$ base of $0.7 \%$ agarose [41]. Experiments were carried out in triplicate. After 40 days, cells were stained with $0.8 \mathrm{mM}$ p-iodonitrotetrazolium violet (Sigma-Aldrich). The in vivo tumorigenicity assay was performed as described previously [41]. A total of $2 \times 10^{6}$ C666-1 cells stably expressing miR-31 or controls were subcutaneously inoculated into the flank of female BALB/c nude mice (nu/nu) (4 mice/construct). Tumor growth was monitored and the tumors were excised at the end of the experiment. All experimental procedures were approved by the Animal Ethics Committee of the Chinese University of Hong Kong.

\section{Luciferase reporter assay}

C666-1 cells at $60 \%$ confluence in 96-well plate were cotransfected with $m i R-31$ mimic and reporter plasmid. After 48 hours of transfection, cells were lysed with $1 \mathrm{X}$ passive lysis buffer (Promega) at room temperature for 20 minutes. The lysates were then transferred to a 96-well ELISA plate and enzyme activities were assayed using the Dual Luciferase Reporter Kit (Promega).

\section{Western blotting}

By western blotting, the expression of various proteins in the miR-31 transfected and siRNA-treated NPC cells was detected. The antibodies against p21 Waf1/Cip1 (Abcam), Phospho-p53 (Ser15) (Abcam), HIF1 $\alpha$ (Abcam), FIH1 (Santa Cruz), MCM2 (Santa Cruz) and ACTIN (Santa Cruz) were used.

\section{Additional files}

Additional file 1: Figure S1. Heat map of expression profiles of differentially expressed miRNAs in immortalized normal epithelial cell line NP69 and NPC tumor lines. The normalized data was log2-transformed and each miRNA was scaled among all the samples. Hierarchical clustering with average linkage algorithm and using one-minus correlation for determination of similarity was performed to cluster the samples and miRNAs. High expression is depicted as red while green box represents low expression.

Additional file 2: Figure S2. High resolution array- $\mathrm{CGH}$ analysis of chromosome 9p21 region in three NPC xenografts, (a) xeno-99186, (b) xeno-1915, and (c) xeno-2117. The locations of miR-31, CDKN2A/p16 and DMRTA1 are indicated.

Additional file 3: Figure S3. Ectopic expression of miR-31 did not suppress the expression of NIK, E2F2, RDX, RhoA and MCM7 in NPC cells. By western blotting, no significant reduction of several reported miR-31 targets including NIK, E2F2, RDX, RhoA and MCM7 were detected in miR-31-transfected C666-1 cells.

Additional file 4: Figure S4. Overexpression of MCM2 and $\mathrm{FIH1}$ in NPC tumor lines. By western blotting, high $\mathrm{MCM} 2$ and $\mathrm{FIH1}$ expression were detected in C666-1 and the xenografts. Weak expression of both MCM and $\mathrm{FIH1}$ were found in the immortalized nasopharyngeal epithelial cells NP69.

Additional file 5: Figure S5. LMP1 expression in NPC cell line and xenografts. The expression of LMP1 in NPC cell line and xenografts was determined by quantitative RT-PCR. By immunohistochemistry staining, LMP1 expression in C15, C17 and xeno-2117 was shown. The assays were performed as we previously described [43]

Additional file 6: Table S1. The characteristics of NPC patients involved in this study. 
Additional file 7: Table S2. List of primer sequences used in PCR, qRT-PCR, MSP and bisufite sequencing analysis.

Additional file 8: Table S3. List of siRNA sequences used in this study.

\section{Abbreviations}

NPC: Nasopharyngeal carcinoma; EBV: Epstein-Barr virus; X666: Xeno-666; X2117: Xeno-2117; X1915: Xeno-1915; X99186: Xeno-99186; miRNA: microRNA.

\section{Competing interests}

The authors declare that they have no competing interests.

\section{Authors' contributions}

KWL, CCMC, and GTYC designed the study; CCMC, GTYC, SWML, KWC, SPS and KML carried out experiments; KFT, RKCN, TTCY, PB, XYG, SWT provided the NPC tumor models, primary tumor specimens and clinical data; KWL, KFT, CCMC, GTYC, SWML were involved in data analysis and writing the paper. All authors had final approval of the submitted manuscript.

\section{Acknowledgements}

The research was supported by Focus Investigation Scheme-A from the Chinese University of Hong Kong, and Hong Kong Research Grant Council - GRF (470413, 470312, 471211), CRF (CUHK8/CRF/11R), AoE NPC (AoE/M-06/08), Theme-Based Research Scheme (T12-403/11 and T12-401/13-R).

\section{Author details}

'Department of Anatomical and Cellular Pathology, State Key Laboratory in Oncology in South China, Prince of Wales Hospital, The Chinese University of Hong Kong, Hong Kong, People's Republic of China. ${ }^{2}$ Li Ka Shing Institute of Health Science, The Chinese University of Hong Kong, Hong Kong, People's Republic of China. ${ }^{3}$ Department of Obstetrics and Gynecology, Prince of Wales Hospital, The Chinese University of Hong Kong, Hong Kong, People's Republic of China. ${ }^{4}$ Department of Clinical Oncology, University of Hong Kong, Hong Kong, People's Republic of China. ${ }^{5}$ Department of Clinical Oncology, Queen Elizabeth Hospital, Hong Kong, People's Republic of China. ${ }^{6}$ CNRS-UMR 8126 and Institut de cancérologie Gustave Roussy, Université Paris-Sud-11, 39 rue Camille Desmoulins, F-94805 Villejuif, France. ${ }^{7}$ Department of Anatomy, University of Hong Kong, Hong Kong, People's Republic of China.

Received: 24 May 2014 Accepted: 27 July 2014

Published: 7 August 2014

\section{References}

1. Bartel DP: MicroRNAs: genomics, biogenesis, mechanism, and function. Cell 2004, 116:281-297.

2. He L, Hannon GJ: MicroRNAs: small RNAs with a big role in gene regulation. Nat Rev Genet 2004, 5:522-531.

3. Farazi TA, Spitzer Jl, Morozov P, Tuschl T: miRNAs in human cancer. J Pathol 2011, 223:102-115.

4. Lo AK, Dawson CW, Jin DY, Lo KW: The pathological roles of BART miRNAs in nasopharyngeal carcinoma. J Pathol 2012, 227:392-403.

5. Lo KW, Teo PM, Hui AB, To KF, Tsang YS, Chan SY, Mak KF, Lee JC, Huang DP: High resolution allelotype of microdissected primary nasopharyngeal carcinoma. Cancer Res 2000, 60:3348-3353.

6. Hui AB, Lo KW, Leung SF, Teo P, Fung MK, To KF, Wong N, Choi PH, Lee JC, Huang DP: Detection of recurrent chromosomal gains and losses in primary nasopharyngeal carcinoma by comparative genomic hybridisation. Int J Cancer 1999, 82:498-503.

7. Ivanov SV, Goparaju CM, Lopez P, Zavadil J, Toren-Haritan G, Rosenwald S, Hoshen M, Chajut A, Cohen D, Pass HI: Pro-tumorigenic effects of miR-31 loss in mesothelioma. J Biol Chem 2010, 285:22809-22817.

8. Lin PC, Chiu YL, Banerjee S, Park K, Mosquera JM, Giannopoulou E, Alves P, Tewari AK, Gerstein MB, Beltran H, Melnick AM, Elemento O, Demichelis F, Rubin MA: Epigenetic repression of miR-31 disrupts androgen receptor homeostasis and contributes to prostate cancer progression. Cancer Res 2013, 73:1232-1244.

9. Valastyan S, Reinhardt F, Benaich N, Calogrias D, Szász AM, Wang ZC, Brock JE, Richardson AL, Weinberg RA: A pleiotropically acting microRNA, miR-31, inhibits breast cancer metastasis. Cell 2009, 137:1032-1046.
10. Creighton CJ, Fountain MD, Yu Z, Nagaraja AK, Zhu H, Khan M, Olokpa E, Zariff A, Gunaratne PH, Matzuk MM, Anderson ML: Molecular profiling uncovers a p53-associated role for microRNA-31 in inhibiting the proliferation of serous ovarian carcinomas and other cancers. Cancer Res 2010, 70:1906-1915.

11. Lo KW, Huang DP, Lau KM: p16 gene alterations in nasopharyngeal carcinoma. Cancer Res 1995, 55:2039-2043.

12. Asangani IA, Harms PW, Dodson L, Pandhi M, Kunju LP, Maher CA, Fullen DR, Johnson TM, Giordano TJ, Palanisamy N, Chinnaiyan AM: Genetic and epigenetic loss of microRNA-31 leads to feed-forward expression of EZH2 in melanoma. Oncotarget 2012, 3:1011-1025.

13. Zhang Y, Guo J, Li D, Xiao B, Miao Y, Jiang Z, Zhuo H: Down-regulation of miR-31 expression in gastric cancer tissues and its clinical significance. Med Oncol 2010, 27:685-689.

14. Cheung FM, Pang SW, Yau TK, Chow SK, Lo KW: Nasopharyngeal intraepithelial lesion: latent Epstein-Barr virus infection with malignant potential. Histopathology 2004, 45:171-179.

15. Tsang CM, Yip YL, Lo KW, Deng W, To KF, Hau PM, Lau VM, Takada K, Lui WW, Lung ML, Chen H, Zeng M, Middeldorp JM, Cheung AL, Tsao SW: Cyclin D1 overexpression supports stable EBV infection in nasopharyngeal epithelial cells. Proc Natl Acad Sci U S A 2012, 109:E3473-3482.

16. Lo KW, Huang DP: Genetic and epigenetic changes in nasopharyngeal carcinoma. Semin Cancer Biol 2002, 12:451-462.

17. Augoff K, McCue B, Plow EF, Sossey-Alaoui K: miR-31 and its host gene IncRNA LOC554202 are regulated by promoter hypermethylation in triple-negative breast cancer. Mol Cancer 2012, 11:5.

18. Lau KM, Chan QK, Pang JC, Ma FM, Li KK, Yeung WW, Cheng AS, Feng $\mathrm{H}$, Chung NY, Li HM, Zhou L, Wang Y, Mao Y, Ng HK: Minichromosome maintenance proteins 2, 3 and 7 in medulloblastoma: overexpression and involvement in regulation of cell migration and invasion. Oncogene 2010, 29:5475-5489.

19. Pelletier J, Dayan F, Durivault J, Ilc K, Pécou E, Pouysségur J, Mazure NM: The asparaginyl hydroxylase factor-inhibiting HIF is essential for tumor growth through suppression of the p53-p21 axis. Oncogene 2012, 31:2989-3001.

20. Lo KW, Kwong J, Hui AB, Chan SY, To KF, Chan AS, Chow LS, Teo PM, Johnson PJ, Huang DP: High frequency of promoter hypermethylation of RASSF1A in nasopharyngeal carcinoma. Cancer Res 2001, 61:3877-3881.

21. Flores JF, Walker GJ, Glendening JM, Haluska FG, Castresana JS, Rubio MP, Pastorfide GC, Boyer LA, Kao WH, Bulyk ML, Barnhill RL, Hayward NK, Housman DE, Fountain JW: Loss of the p16INK4a and p15INK4b genes, as well as neighboring 9p21 markers, in sporadic melanoma. Cancer Res 1996, 56:5023-5032.

22. Veerla $S$, Lindgren $D$, Kvist A, Frigyesi A, Staaf J, Persson H, Liedberg F, Chebil G, Gudjonsson S, Borg A, Månsson W, Rovira C, Höglund M: MiRNA expression in urothelial carcinomas: important roles of miR-10a, miR-222, miR-125b, miR-7 and miR-452 for tumor stage and metastasis, and frequent homozygous losses of miR-31. Int J Cancer 2009, 124:2236-2242.

23. Yamagishi M, Nakano K, Miyake A, Yamochi T, Kagami Y, Tsutsumi A, Matsuda Y, Sato-Otsubo A, Muto S, Utsunomiya A, Yamaguchi K, Uchimaru K, Ogawa S, Watanabe T: Polycomb-mediated loss of miR-31 activates NIK-dependent NF-kB pathway in adult T cell leukemia and other cancers. Cancer Cell 2012, 21:121-135.

24. Fuse M, Kojima S, Enokida H, Chiyomaru T, Yoshino H, Nohata N, Kinoshita T, Sakamoto S, Naya Y, Nakagawa M, Ichikawa T, Seki N: Tumor suppressive microRNAs (miR-222 and miR-31) regulate molecular pathways based on microRNA expression signature in prostate cancer. J Hum Genet 2012, 57:691-699.

25. Liu Y, He G, Wang Y, Guan X, Pang X, Zhang B: MCM-2 is a therapeutic target of Trichostatin A in colon cancer cells. Toxicol Lett 2013, 221:23-30.

26. Majid S, Dar AA, Saini S, Chen Y, Shahryari V, Liu J, Zaman MS, Hirata H, Yamamura S, Ueno K, Tanaka Y, Dahiya R: Regulation of minichromosome maintenance gene family by microRNA-1296 and genistein in prostate cancer. Cancer Res 2010, 70:2809-2818.

27. Liu CJ, Tsai MM, Hung PS, Kao SY, Liu TY, Wu KJ, Chiou SH, Lin SC, Chang KW: miR-31 ablates expression of the HIF regulatory factor FIH to activate the HIF pathway in head and neck carcinoma. Cancer Res 2010, 70:1635-1644.

28. Peng H, Kaplan N, Hamanaka RB, Katsnelson J, Blatt H, Yang W, Hao L, Bryar PJ, Johnson RS, Getsios S, Chandel NS, Lavker RM: microRNA-31/factorinhibiting hypoxia-inducible factor 1 nexus regulates keratinocyte differentiation. Proc Natl Acad Sci U S A 2012, 109:14030-14034. 
29. Khan MN, Bhattacharyya T, Andrikopoulos P, Esteban MA, Barod R, Connor T, Ashcroft M, Maxwell PH, Kiriakidis S: Factor inhibiting HIF (FIH-1) promotes renal cancer cell survival by protecting cells from HIF-1a-mediated apoptosis. Br J Cancer 2011, 104:1151-1159.

30. Kondo S, Seo SY, Yoshizaki T, Wakisaka N, Furukawa M, Joab I, Jang KL, Pagano JS: EBV latent membrane protein 1 up-regulates hypoxia-inducible factor 1alpha through Siah1-mediated down-regulation of prolyl hydroxylases 1 and 3 in nasopharyngeal epithelial cells. Cancer Res 2006, 66:9870-9877.

31. Tsao SW, Wang X, Liu Y, Cheung YC, Feng H, Zheng Z, Wong N, Yuen PW, Lo AK, Wong YC, Huang DP: Establishment of two immortalized nasopharyngeal epithelial cell lines using SV40 large T and HPV16E6/E7 viral oncogenes. Biochim Biophys Acta 2002, 1590:150-158.

32. Li HM, Man C, Jin Y, Deng W, Yip YL, Feng HC, Cheung YC, Lo KW, Meltzer PS, Wu ZG, Kwong YL, Yuen AP, Tsao SW: Molecular and cytogenetic changes involved in the immortalization of nasopharyngeal epithelial cells by telomerase. Int J Cancer 2006, 119:1567-1576.

33. Cheung ST, Huang DP, Hui AB, Lo KW, Ko CW, Tsang YS, Wong N, Whitney BM, Lee JC: Nasopharyngeal carcinoma cell line (C666-1) consistently harbouring Epstein-Barr virus. Int J Cancer 1999, 83:121-126.

34. Huang DP, Ho JH, Poon YF, Chew EC, Saw D, Lui M, Li CL, Mak LS, Lai SH, Lau WH: Establishment of a cell line (NPC/HK1) from a differentiated squamous carcinoma of the nasopharynx. Int J Cancer 1980, 26:127-132.

35. Lo AK, Lo KW, Tsao SW, Wong HL, Hui JW, To KF, Hayward DS, Chui YL, Lau YL, Takada K, Huang DP: Epstein-Barr virus infection alters cellular signal cascades in human nasopharyngeal epithelial cells. Neoplasia 2006, 8:173-180.

36. Busson P, Ganem G, Flores P, Mugneret F, Clausse B, Caillou B, Braham K, Wakasugi $H$, Lipinski M, Tursz T: Establishment and characterization of three transplantable EBV-containing nasopharyngeal carcinomas. Int $J$ Cancer 1988, 42:599-606.

37. Huang DP, Ho JH, Chan WK, Lau WH, Lui M: Cytogenetics of undifferentiated nasopharyngeal carcinoma xenografts from southern Chinese. Int J Cancer 1989, 43:936-939.

38. Lun SW, Cheung ST, Cheung PF, To KF, Woo JK, Choy KW, Chow C, Cheung CC, Chung GT, Cheng AS, Ko CW, Tsao SW, Busson P, Ng MH, Lo KW: CD44+ cancer stem-like cells in EBV-associated nasopharyngeal carcinoma. PLoS One 2012, 7:e52426.

39. Kwong J, Lo KW, To KF, Teo PM, Johnson PJ, Huang DP: Promoter hypermethylation of multiple genes in nasopharyngeal carcinoma. Clin Cancer Res 2002, 8:131-137.

40. Chow LS, Lo KW, Kwong J, Wong AY, Huang DP: Aberrant methylation of RASSF4/AD037 in nasopharyngeal carcinoma. Oncol Rep 2004, 12:781-787.

41. Chung GT, Lung RW, Hui AB, Yip KY, Woo JK, Chow C, Tong CY, Lee SD, Yuen JW, Lun SW, Tso KK, Wong N, Tsao SW, Yip TT, Busson P, Kim H, Seo JS, O'Sullivan B, Liu FF, To KF, Lo KW: Identification of a recurrent transforming UBR5-ZNF423 fusion gene in EBV-associated nasopharyngeal carcinoma. J Pathol 2013, 231:158-167.

42. Lo AK, Huang DP, Lo KW, Chui YL, Li HM, Pang JC, Tsao SW: Phenotypic alterations induced by the Hong Kong-prevalent Epstein-Barr virus-encoded LMP1 variant (2117-LMP1) in nasopharyngeal epithelial cells. Int J Cancer 2004, 109:919-925.

43. Chung GT, Lou WP, Chow C, To KF, Choy KW, Leung AW, Tong CY, Yuen JW, Ko CW, Yip TT, Busson P, Lo KW: Constitutive activation of distinct $\mathrm{NF}-\mathrm{KB}$ signals in EBV-associated nasopharyngeal carcinoma. J Pathol 2013, 231:311-322.

doi:10.1186/1476-4598-13-184

Cite this article as: Cheung et al: miR-31 is consistently inactivated in EBV-associated nasopharyngeal carcinoma and contributes to its tumorigenesis. Molecular Cancer 2014 13:184.

\section{Submit your next manuscript to BioMed Central and take full advantage of:}

- Convenient online submission

- Thorough peer review

- No space constraints or color figure charges

- Immediate publication on acceptance

- Inclusion in PubMed, CAS, Scopus and Google Scholar

- Research which is freely available for redistribution

Submit your manuscript at www.biomedcentral.com/submit
C Biomed Central 